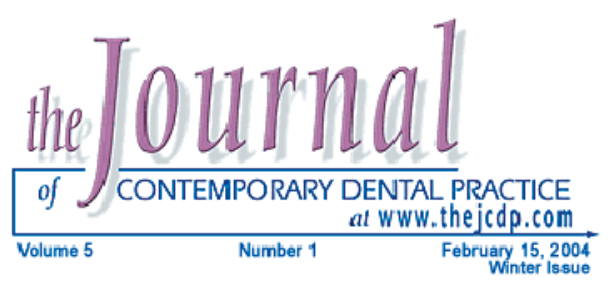

\title{
Professional Vital Bleaching Using a Thin and Concentrated Peroxide Gel on Whitening Strips: An Integrated Clinical Summary
}

\author{
Robert W. Gerlach, DDS, MPH; Matthew L. Barker, PhD
}

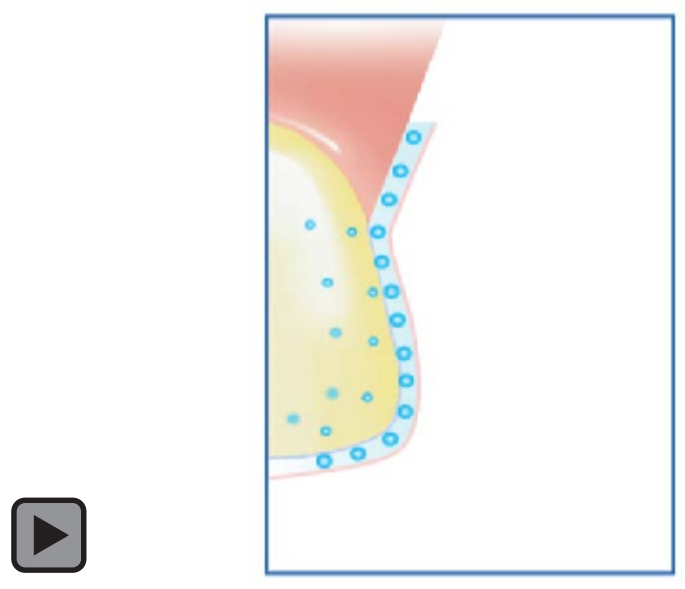

Abstract

Rapid innovation in vital bleaching continues to expand the number of treatment options available to patients, particularly in the area of at-home whitening. The development of bleaching strips represented a new paradigm in the delivery of peroxide. The efficacy and safety of bleaching strip systems delivering up to $6.5 \%$ hydrogen peroxide has been established in numerous randomized clinical trials. In 2003, a novel bleaching strip with $14 \%$ hydrogen peroxide (Crest ${ }_{\circledast}$ Whitestrips ${ }^{\circledast}$ Supreme) was introduced. This advanced system carries a thinner but more concentrated gel on each strip, resulting in a relatively similar total amount of peroxide as compared to other strip systems. This 2-variable change, higher concentration gel with lowered gel volume translates to improved whitening without adversely affecting oral soft tissue tolerability and irritation. This paper provides an integrated review of 9 comparative clinical trials evaluating the whitening response (six trials) and safety (nine trials) of this novel vital bleaching system. Efficacy results for the $14 \%$ hydrogen peroxide strips were significantly $(p<0.05)$ better than the placebo or pooled positive controls evaluated in the clinical trials assessing tooth color or shade. Adverse events were similar in type to the other vital bleaching systems. Overall, the research of 408 patients showed generally better efficacy and similar to or better tolerability for the $14 \%$ hydrogen peroxide strips compared to a selected group of marketed positive bleaching controls.

Keywords: Vital tooth bleaching, bleaching strips, hydrogen peroxide, tooth whitening, blind, clinical, review

Citation: Gerlach RW, Barker ML. Professional Vital Bleaching Using a Thin and Concentrated Peroxide Gel on Whitening Strips: An Integrated Clinical Summary. J Contemp Dent Pract 2004 February;(5)1:001-017.

(c) Seer Publishing 
Introduction

The past months have been characterized by rapid innovation in vital bleaching, especially with the advent of new in-office options for immediate care and the emerging popularity of the directto-consumer systems. Such is the case with the recently developed whitening strip - a novel bleaching system that uses a flexible polyethylene strip to deliver a hydrogen peroxide bleaching gel to the anterior dentition. "This "trayless" delivery system is reported to offer advantages with respect to overall peroxide dose, contact time, and ease-of-use compared to other delivery systems. $^{2}$

Evidence of the safe and efficacious use of the strip bleaching systems has been established in a series of randomized clinical trials relative to various marketed or experimental controls in studies involving different populations and time points..$^{3-16}$ Use of whitening strips was well-tolerated, with transient tooth sensitivity and minor oral irritation representing the most prominent side effects. The majority of events were mild in severity. In one integrated summary of 13 whitening strip clinical studies, only $1 \%$ of subjects who used strips discontinued treatment early because of tooth sensitivity or oral irritation. ${ }^{3}$

In composite, the published clinical data on whitening strips represents one of the most comprehensive bodies of research on vital bleaching in the literature. The trials were conducted at various sites by different investigators using several study designs and measurement methods. This extensive clinical research program evaluated whitening strip effectiveness and safety across a broad range of populations, formulations, and usage conditions. Since the mid-year 2000 introduction of Crest ${ }_{\oplus}$ Whitestrips $^{\oplus}$, there are already over 80 abstracts and publications on the clinical and preclinical effectiveness and safety of stripbased vital bleaching.

\section{Visit http://www.dentalcare.com/soap/cws/ for} Crest Whitestrips Product Research.

Recently, a novel bleaching strip was developed with $14 \%$ hydrogen peroxide $\left(\right.$ Crest $_{\circledast}$ Whitestrips $^{\circledR}$ Supreme). Packaged in a 3-week kit with a powered brush and anticavity whitening dentifrice, this system is reported to represent a new option
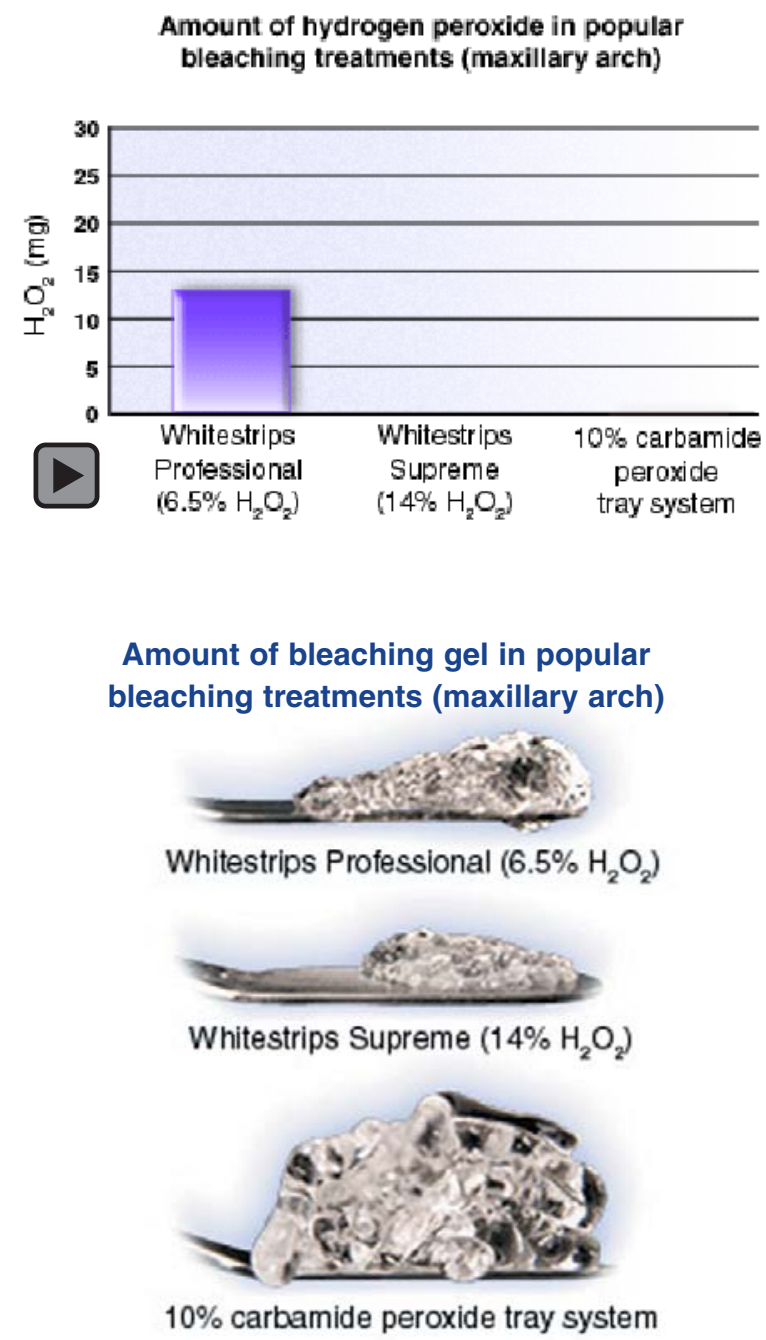

for professional at-home tooth whitening that does not require custom tray fabrication. While this system has a higher concentration of hydrogen peroxide relative to the marketed Crest $_{\circledast}$ Professional Whitestrips ${ }^{\circledast}$ (14\% versus $\left.6.5 \%\right)$, the total amount of hydrogen peroxide is approximately the same. A maxillary strip from the Crest Whitestrips Supreme system carries $100 \mathrm{mg}$ of bleaching gel with $14 \%$ hydrogen peroxide or $14 \mathrm{mg}$ of hydrogen peroxide. ${ }^{17}$ For comparison, each maxillary strip from the Crest Professional Whitestrips system has $200 \mathrm{mg}$ bleaching gel with $6.5 \%$ hydrogen peroxide, or $13 \mathrm{mg}$ of hydrogen peroxide.

The primary advantage of the $14 \%$ hydrogen peroxide strip versus the $6.5 \%$ hydrogen peroxide strip is theorized to be more effective whitening. With this higher concentration strip, peroxide mol- 


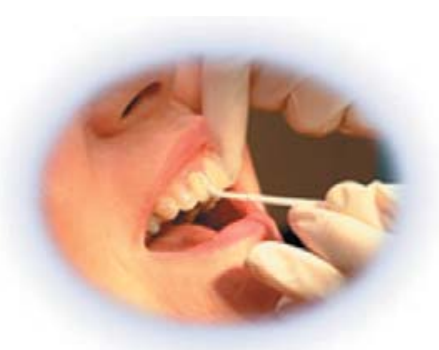

From Teeth

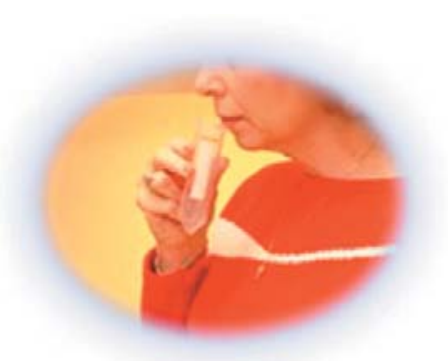

From Strip

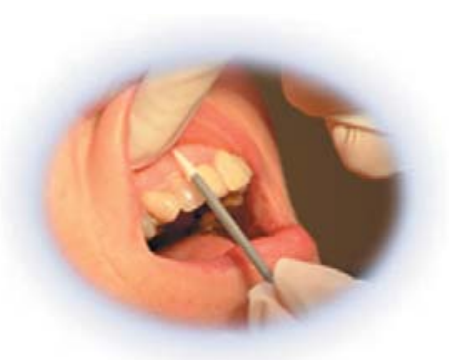

From Gingiva

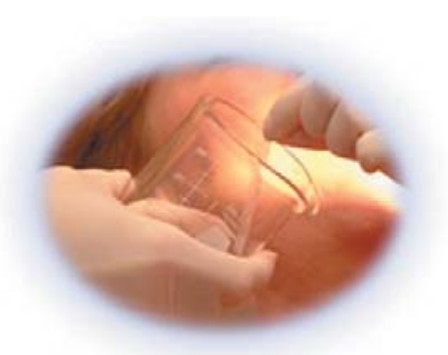

From Saliva ecules interact with and diffuse through enamel more efficiently following diffusion principles. ${ }^{18}$ This increased diffusion is believed to contribute to better peroxide availability within the tooth, especially at the level of the dentinoenamel junction, where acquired chromagenic material is oxidized through normal chemical processes, resulting in whiter teeth. However, the same mechanism that promotes whitening could plausibly affect oral soft tissue response. There is considerable practical evidence of this with the higher concentration, in-office whitening systems, where treatment is typically preceded by the application of a barrier (such as a rubber dam or other device) to limit contact of the peroxide gel with gingival tissues during bleaching. To limit such effects, the gel layer on the new concentrated strips was reduced, leaving the total amount of peroxide exposure for the two professional strips essentially unchanged.

Using the strip as a barrier, application of the thin concentrated gel is reported to yield extended peroxide residency on teeth for up to 1-hour, with only limited oral soft tissue exposure. ${ }^{19}$ The intraoral peroxide degradation profile demonstrated rapid peroxide degradation from the thin gel on gingiva. After 5 minutes, the mean gingival peroxide concentration fell to $0.4 \%$, which is less than one-thirtieth of the starting concentration on strips. This differed from the peroxide recovered from teethwhere there was a 20-40-fold higher concentration compared to gingiva. This peroxide degradation profile provides the basis for a higher concentration, thin gel system for improved whitening without additional oral irritation. Following this kinetic model, a series of studies were conducted to evaluate clinical response with the thin $14 \%$ hydrogen peroxide gel pre-dispensed on a flexible whitening strip.

\section{Clinical Plan}

Nine randomized clinical trials were conducted at different clinical sites to evaluate the $14 \%$ hydrogen peroxide strip relative to various experimental controls. The research was conducted with independent institutional review and informed consent in accordance with the appropriate national and international guidelines for human research and standard operating procedures. Study design, clinical methods, and performance criteria were consistent with the preceding extensive research on whitening strips. Each study was under the direction of a qualified investigator with considerable clinical trials experience in the area of vital bleaching.

Each clinical trial was designed to address a specific research question. (A brief description of the study design and objectives for each trial is listed below.) Experimental controls, either a positive control professional at-home bleaching system or placebo, were selected to meet each study's specific needs. 


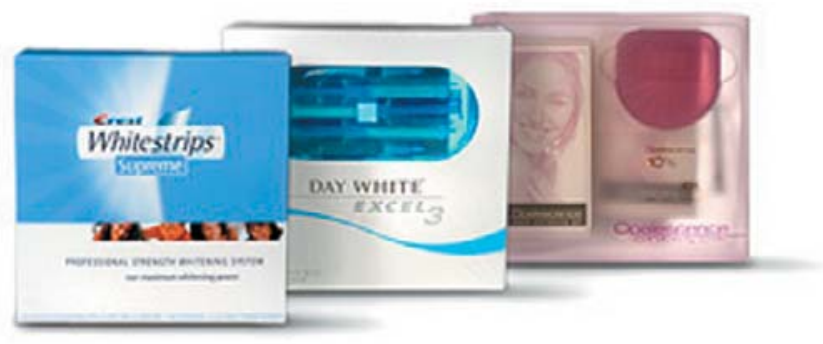

Examples of Products Tested

1. Randomized, double-blind, placebo-controlled clinical trial to evaluate the efficacy, safety, and tolerability of $14 \%$ hydrogen peroxide strips with extended 6-weeks use.

2. Randomized and controlled, examiner-blind, clinical trial to evaluate the whitening efficacy and safety of $14 \%$ hydrogen peroxide strips among teenagers relative to one of the lower concentration (10\% carbamide peroxide), tray-based positive controls that had previously earned the American Dental Association (ADA) "Seal of Acceptance."

3. Randomized, double-blind, placebo controlled clinical trial to evaluate the color stability and safety of $14 \%$ hydrogen peroxide strips over a 3-month post-treatment monitoring period.

4. Randomized and controlled, examiner-blind, clinical trial to evaluate the whitening efficacy and safety of $14 \%$ hydrogen peroxide strips relative to an intermediate concentration (16\% carbamide peroxide), tray-based positive control.

5. Randomized, examiner-blind, crossover study conducted among individuals who had a history of tooth sensitivity and/or oral irritation during a previous vital bleaching clinical trial to evaluate the safety and tolerability of $14 \%$ hydrogen peroxide strips relative to a $6.5 \%$ hydrogen peroxide strip-based positive control.

6. Randomized, examiner-blind clinical trial to evaluate the whitening efficacy and safety of $14 \%$ hydrogen peroxide strips relative to one of the higher concentration $(9.5 \%$ hydrogen peroxide) tray-based positive controls.

7. Randomized and controlled, examiner-blind clinical trial to evaluate the comparative safety and tolerability of $14 \%$ hydrogen peroxide strips relative to one of the higher concentration ( $20 \%$ carbamide peroxide), tray-based positive controls.
8. Randomized, double-blind, placebo-controlled clinical trial to compare shade change and safety of 3-week, twice daily use of $14 \%$ hydrogen peroxide strips to placebo, using measurement criteria recommended in the ADA guidelines for home-use tooth whitening products.

9. Randomized and controlled, examiner-blind clinical trial to evaluate the comparative safety and tolerability of $14 \%$ hydrogen peroxide strips relative to one of the higher concentration ( $30 \%$ carbamide peroxide), tray-based positive controls.

The research was conducted at 7 different academic or clinical research settings. This combination of sites and researchers was desired to obtain the broadest possible perspective on clinical response to the novel bleaching strip.

Each clinical study had an experimental control (Table 1). Three trials were placebo-controlled. These double-blind trials allowed for the direct assessment of causality with respect to safety endpoints. Five studies used one of the popular custom tray-based vital bleaching systems dispensed by professionals for at-home whitening as a positive experimental control. One sensitivity study used Crest Professional Whitestrips as the positive experimental control. Such controls allow for the direct comparison of the novel $14 \%$ strip relative to marketed controls that are regularly used in dental practice. Because professional systems differ with respect to peroxide source, formulation, and concentration, we selected various marketed controls and regimens to provide perspective on the comparative response versus a range of peroxide concentrations and sources. Four of these studies specifically evaluated the $14 \%$ hydrogen peroxide bleaching strip relative to the highest peroxide concentration systems marketed by leading manufacturers for at-home use at the time of testing (Crest Professional Whitestrips, Day White $9.5 \%$, Opalescence 20\% F, Rembrandt XTRA Comfort 30\%).

In composite the research evaluated normal and extended use of $14 \%$ hydrogen peroxide bleaching strips as well as post-treatment status. Efficacy and safety measurements were collected in accordance with standard methods used in numerous preceding whitening clinical trials. ${ }^{3}$ Tooth color 
Table 1. Study Description.

\begin{tabular}{|c|c|c|c|}
\hline Study & $\mathbf{N} \mathbf{P}$ & Treatment Description & Treatment Regimen \\
\hline 1 & 39 & $\begin{array}{l}\text { Crest Whitestrips Supreme } \\
\text { Placebo Strips }\end{array}$ & 30 min BID, 6 weeks \\
\hline 2 & 60 & $\begin{array}{l}\text { Crest Whitestrips Supreme } \\
\text { Opalescence } 10 \%\end{array}$ & $\begin{array}{l}30 \text { min BID, } 2-3 \text { weeks/arch } \\
\text { Ovemight, } 2-3 \text { weeks/arch }\end{array}$ \\
\hline 3 & 50 & $\begin{array}{l}\text { Crest Whitestrips Supreme } \\
\text { Placebo Strip }\end{array}$ & 30 min BID, 3 weeks \\
\hline 4 & 69 & $\begin{array}{l}\text { Crest Whitestrips Supreme } \\
\text { Nite White Excel3 16\% }\end{array}$ & $\begin{array}{l}30 \text { min BID, } 3 \text { weeks } \\
2-4 \text { hours QD-BID, } 10 \text { days }\end{array}$ \\
\hline 5 & $18^{b}$ & $\begin{array}{l}\text { Crest Whitestrips Supreme } \\
\text { Crest Prof. Whitestrips }\end{array}$ & 30 min BID, 1 week \\
\hline 6 & 39 & $\begin{array}{l}\text { Crest Whitestrips Supreme } \\
\text { Day White } 9.5 \%\end{array}$ & $\begin{array}{l}30 \text { min BID, } 3 \text { weeks } \\
30 \text { min BID, } 9 \text { days }\end{array}$ \\
\hline 7 & 60 & $\begin{array}{l}\text { Crest Whitestrips Supreme } \\
\text { Opalescence } 20 \% \mathrm{~F}\end{array}$ & $\begin{array}{l}30 \text { min BID, } 3 \text { weeks } \\
\text { Ovemight, } 14 \text { days }\end{array}$ \\
\hline 8 & 29 & $\begin{array}{l}\text { Crest Whitestrips Supreme } \\
\text { Placebo Strip }\end{array}$ & 30 min BID, 3 weeks \\
\hline 9 & 44 & $\begin{array}{l}\text { Crest Whitestrips Supreme } \\
\text { Rembrandt XTRA Comfort }\end{array}$ & $\begin{array}{l}30 \text { min BID, } 3 \text { weeks } \\
30 \text { min BID, } 10 \text { days }\end{array}$ \\
\hline
\end{tabular}

efficacy was measured in five trials (Studies 1 , 2, 3, 4, and 6 above) using a standard, objective method involving archival-quality digital images collected from the anterior dentition. Safety was measured by treatment-blinded examination of the oral soft and hard tissues, along with subject interview to assess the presence or absence of symptoms (tooth sensitivity and oral irritation) that may have occurred at any time during treatment. The nature of any adverse events, along with information relating to onset, severity, and duration, were recorded along with examiner-assigned causality according to pharmaceutical industry research standards. For analysis, all adverse events were classified using the standard COSTART coding nomenclature. In addition, one study used evaluation methods described in the ADA guidelines for home-use tooth whitening products. ${ }^{20}$ In that trial (Study \#8 above), a trained and calibrated examiner measured tooth shade using a standard, value-oriented collection of 16 tooth-shaped tabs $\left(\right.$ VitaPan ${ }^{\oplus}$ Classical, VITA Zahnfabrik, H. Rauter $\mathrm{GmbH} \&$ Co., Bad Sackingen, Germany). One of the efficacy endpoints was the proportion of maxillary incisors in the Crest Whitestrips group having at least a two shade decrease (increase in whiteness) over time. The proportion of evaluable teeth in the $14 \%$ strip system having at least a two Vita

\section{Digital Imaging System}

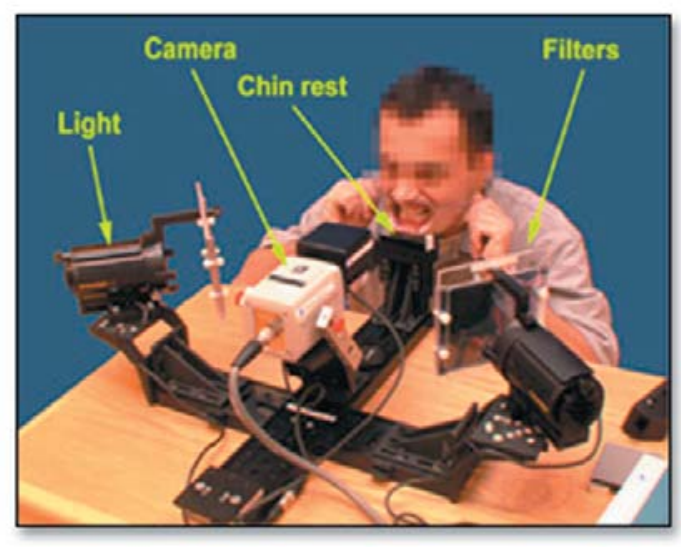




\section{Results}

shade increase in "whiteness" was calculated to determine whether the observed proportion was $95 \%$ or greater at end-of-treatment. In addition, safety was assessed by the absence of irreversible side effects associated with use of the test product, including notably, assessment of the effect of treatment on gingivitis and plaque.

In the integrated analysis, individual subject outcomes were pooled into three categories to provide a general framework to assess the clinical response of the novel strips: experimental strips (Crest Whitestrips Supreme), positive controls (6 peroxide-containing professional at-home tray or strip systems), or placebo strips (no peroxide). Effectiveness was compared between categories using a general linear model (for tooth color) or analysis of covariance (for tooth shade) adjusting for starting color/shade and/or study effects, as appropriate. All between-category testing was two-sided $(p<0.05)$.

\section{Study Population}

The composite research involved 348 adult volunteers who provided informed consent, and 60 teenagers, for whom both parental informed consent and child assent was obtained. By treatment, there were a total of 212 subjects who used the $14 \%$ bleaching strips, 152 who used one of the positive bleaching controls, and 60 who used placebo strips. This sample size in each group exceeded the total sample size of 50 recommended in the ADA guidelines for home-use tooth whitening products.

One study (Table 1, \#5) was a crossover design, where subjects used both $14 \%$ hydrogen peroxide strips and a positive control. Overall, the population exhibited considerable diversity with respect to age, gender, and ethnicity (Table 2). Subjects ranged from 12-72 years of age. Both genders were well-represented. Treatment groups were balanced overall with respect to demographic parameters.

Table 2. Demographic Characteristics by Group - Nine Randomized Controlled Trials.

\begin{tabular}{|c|c|c|c|}
\hline $\begin{array}{c}\text { Baseline } \\
\text { Characteristic } \\
\text { Statistic }\end{array}$ & $\begin{array}{c}14 \% \mathrm{H}_{2} \mathrm{O}_{2} \text { Strips } \\
(n=212)\end{array}$ & $\begin{array}{c}\text { Positive Controls } \\
(n=152)\end{array}$ & $\begin{array}{l}\text { Placebo Strips } \\
\qquad(n=60)\end{array}$ \\
\hline \multicolumn{4}{|l|}{ Age (Years) } \\
\hline Mean (SD) & $33.8(13.85)$ & $33.1(13.74)$ & 35.7 (14.18) \\
\hline Min - Max & $12-70$ & $12-72$ & $18-66$ \\
\hline \multicolumn{4}{|l|}{$\operatorname{Sex}$} \\
\hline Female & $134(63.2 \%)$ & $94(61.8 \%)$ & $35(58.3 \%)$ \\
\hline Male & $78(36.8 \%)$ & $58(38.2 \%)$ & $25(41.7 \%)$ \\
\hline \multicolumn{4}{|l|}{ Ethnicity } \\
\hline American Indian & $0(0.0 \%)$ & $1(0.7 \%)$ & $0(0.0 \%)$ \\
\hline Asian & $9(4.2 \%)$ & $3(2.0 \%)$ & $2(3.3 \%)$ \\
\hline Black & $22(10.4 \%)$ & $17(11.2 \%)$ & $6(10.0 \%)$ \\
\hline White & $146(68.9 \%)$ & $104(68.4 \%)$ & $35(58.3 \%)$ \\
\hline Hispanic & $21(9.9 \%)$ & $22(14.5 \%)$ & $8(13.3 \%)$ \\
\hline Indian Subcontinent & $10(4.7 \%)$ & $3(2.0 \%)$ & $4(6.7 \%)$ \\
\hline Multi-racial & $4(1.9 \%)$ & $2(1.3 \%)$ & $5(8.3 \%)$ \\
\hline
\end{tabular}




\section{Effectiveness}

The primary efficacy endpoint in 5 comparative studies (Table 1, \#1, 2, 3, 4, and 6) was reduction in yellowness $\left(\Delta b^{*}\right)$, which has been previously reported to represent the most perceptually relevant color measurement in vital bleaching clinical trials. ${ }^{9}$ The pooled sample included 110 subjects assigned to $14 \%$ hydrogen peroxide strips over a 2-6 week usage period. Response was approximately normally distributed with $69 \%$ of subjects experiencing between 2-5 units improvement in $\Delta \mathrm{b}^{*}$. Approximately $83 \%$ of subjects in the pooled $14 \%$ bleaching strip group experienced a 2-unit or greater improvement in $\Delta b^{*}$, while $60 \%$ experienced at least a 3-unit or greater improvement in $\Delta \mathrm{b}^{*}$ (Figure 1).

The comparative research evaluated the pooled color response of $14 \%$ hydrogen peroxide strips, the positive controls, and placebo (Table 3).

Relative to baseline, the pooled $14 \%$ strip aroup exhibited a highly significant $(p<0.0001)$ reduction in yellowness. Mean (SD) $\Delta b^{*}$ was -3.31 (1.597). There was a similar, highly significant color improvement for other individual $\left(\Delta \mathrm{L}^{*}\right.$ and $\left.\Delta \mathrm{a}^{*}\right)$ and composite $\left(\Delta \mathrm{E}^{*}\right.$ and $\left.\Delta \mathrm{W}^{*}\right)$ color parameters. Color response in the pooled placebo group was not significantly different $(p>0.60)$ from "zero" as evidenced by a mean (SD) $\Delta b^{*}$ of 0.04 (0.490). Relative to placebo, the pooled 14\% strip group exhibited highly significant $(p<0.0001)$ improvements in all individual and composite color parameters. Overall, the pooled positive control group had a highly significant $(p<0.0001)$ reduction in yellowness, and improvement in other color parameters. Mean (SD) $\Delta b^{*}$ in this combined group was -2.21 (1.311). Relative to the pooled positive controls, the $14 \%$ hydrogen peroxide group exhibited significant $(p<0.05)$ improvement in the individual parameters $\Delta \mathrm{b}^{*}$ and $\Delta \mathrm{L}^{*}$ as well as the composite parameters $\Delta \mathrm{E}^{\star}$ and $\Delta \mathrm{W}^{*}$.

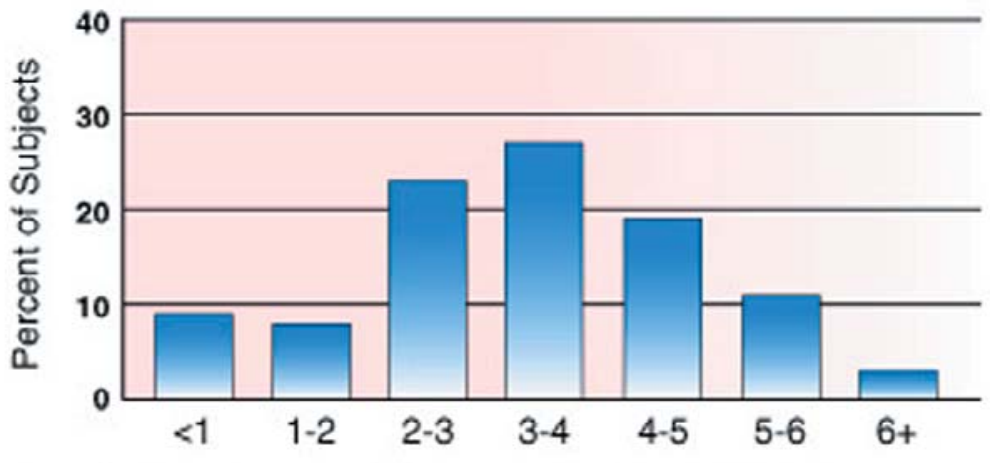

Figure 1. Mean Reduction in Yellowness by Subject 14\% hydrogen peroxide strips, Five Clinical Trials

Table 3. Color or Shade Mean (SD) Change from Baseline - Evaluable Subjects, Six Clinical Trials.

\begin{tabular}{|c|c|c|c|}
\hline $\begin{array}{l}\text { Measurement / } \\
\text { Endpoint }\end{array}$ & $14 \% \mathrm{H}_{2} \mathrm{O}_{2}$ Strips & Postive Controls & Placebo Strips \\
\hline Collor & $N=110$ & $N=77$ & $N=37$ \\
\hline$\Delta \mathrm{b}^{*}$ & $-3.31(1.597)$ & $-2.21(1.311)$ & $0.04(0.490)$ \\
\hline$\Delta L^{*}$ & $2.84(1.384)$ & $2.45(1.123)$ & $0.02(0.574)$ \\
\hline$\Delta \mathrm{a}^{*}$ & $-0.97(0.681)$ & $-0.84(0.580)$ & $0.00(0.309)$ \\
\hline$\Delta W^{*}$ & $-4.27(1.935)$ & $-3.35(1.531)$ & $0.00(0.505)$ \\
\hline$\Delta \mathrm{E}^{\star}$ & $4.60(1.917)$ & $3.53(1.557)$ & $0.73(0.343)$ \\
\hline Shade & $N=13$ & & $N=15$ \\
\hline$\Delta$ Shade (4 Teeth) & $-8.01(2.379)$ & & $-0.76(2.134)$ \\
\hline$\Delta$ Shade (6 Teeth) & $-8.51(1.925)$ & & $-1.04(1.892)$ \\
\hline
\end{tabular}


The scatterplot of two-parameter whitening $\left(\Delta b^{*}\right.$ versus $\Delta \mathrm{L}^{*}$ ) illustrated the individual whitening response with the strips, and the positive and placebo controls (Figure 2). Most of the placebo subjects clustered generally around zero for $\Delta \mathrm{b}^{*}$ and $\Delta \mathrm{L}$. In contrast the overwhelming majority of subjects using one of the peroxide-containing products (strips or trays) experienced two parameter $\left(b^{*} \& L^{*}\right)$ improvements in tooth color with treatment. While there was considerable variability in whitening response, the $14 \%$ hydrogen peroxide group experienced the greatest absolute two-parameter improvement compared to the pooled positive control products or placebo.

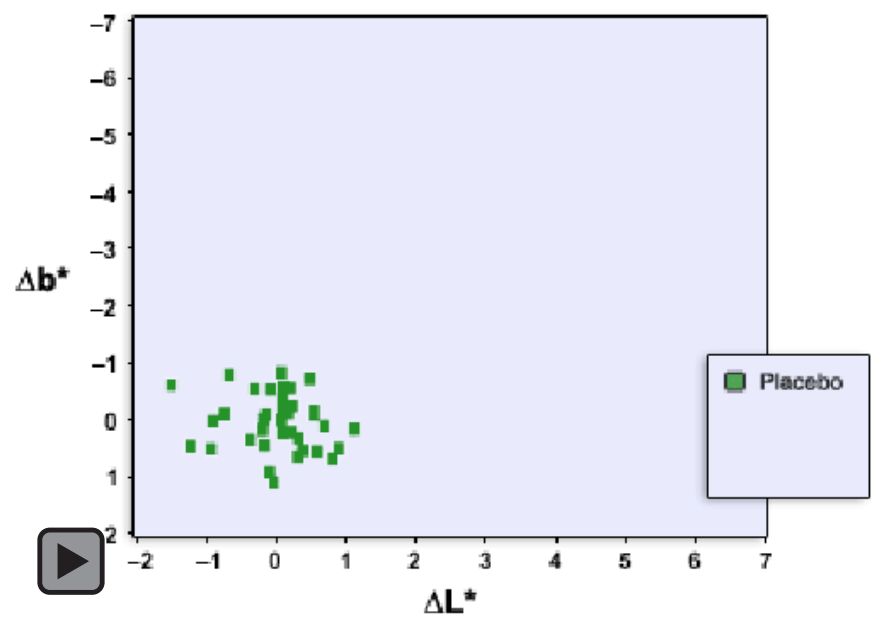

Figure 2. Individual Subject Color Response: Strips, Positive Controls, and Placebo Controls

One study (Table 1, \#8) used tooth shade as an endpoint with shade change measured on the 6 maxillary anterior teeth. After three weeks of treatment, $96 \%$ of incisors in the $14 \%$ strip group exhibited at least a 2-shade improvement. Similar results were observed for the incisors and cuspids, where $97 \%$ of those teeth exhibited at least a 2-shade improvement. As such, the strips met the ADA end-of-treatment performance criteria for shade improvement; to be considered as efficacious, at least $95 \%$ of maxillary incisor teeth had to exhibit at least a two shade improvement versus baseline at end-of-treatment.

In this shade study clinical response in the 14\% strip group was approximately normally distributed, with $69 \%$ of subjects experiencing a 7-10 shade improvement. All subjects (100\%) averaged at least a 4-shade improvement, while approximately $92 \%$ of subjects in the pooled $14 \%$ strip group experienced a 6 -unit or greater shade improvement (Figure 3).

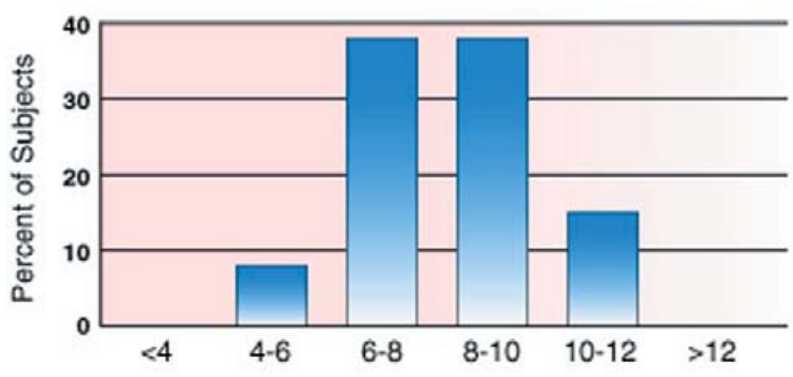

Figure 3. Mean Shade Improvement by Subject $14 \%$ hydrogen peroxide strips

Compared to baseline, the $14 \%$ hydrogen peroxide strip group exhibited a highly significant $(p<$ 0.0001 ) reduction in shade at end-of-treatment. Mean (SD) shade change was -8.0 (2.38) for the 4 maxillary incisor teeth and -8.5 (1.93) for the 6 maxillary anterior teeth (Table 3 ). In contrast, the placebo group exhibited no more than a 1-shade change on average. Treatments differed significantly $(p<0.0001)$ with respect to shade change after 3 weeks.

\section{Safety}

Tooth sensitivity and oral irritation were specifically monitored in each study at each time point, because these two events have been widely recognized as the most common adverse events with vital bleaching. Overall, $43 \%$ of strip users reported tooth sensitivity and $23 \%$ reported oral irritation (Figure 4). Clinically detected oral irritation was less common. For these events, study results demonstrated use of $14 \%$ hydrogen peroxide strips was well tolerated both in the absolute and relative to the other professional at-home systems tested in this research (Table 4).

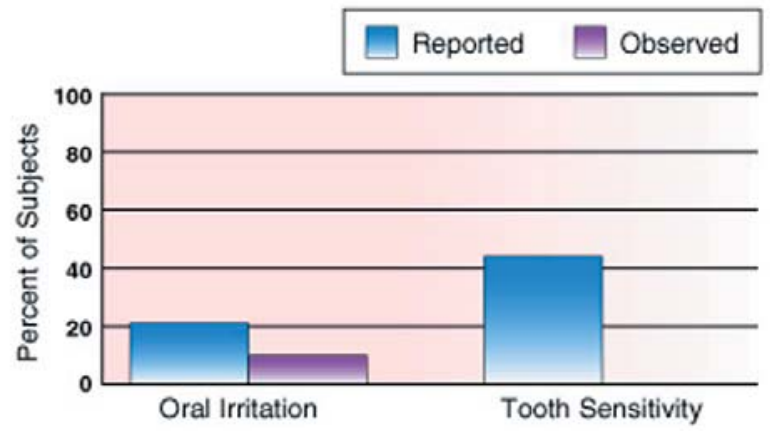

Figure 4. Oral Irritation and Tooth Sensitivity $14 \%$ hydrogen peroxide strips, All Studies 
Table 4. Possible or Probable Treatment Related Oral Irritation or Tooth Sensitivity - All Subjects Treated, Nine Clinical Trials.

\begin{tabular}{|c|c|c|c|}
\hline & $\begin{array}{c}14 \% \mathrm{H}_{2} \mathrm{O}_{2} \text { Strips } \\
\mathrm{N}=212)\end{array}$ & $\begin{array}{l}\text { Positive Controls } \\
(\mathrm{N}=152)\end{array}$ & $\begin{array}{l}\text { Placebo Strips } \\
\qquad(\mathbf{N}=60)\end{array}$ \\
\hline $\begin{array}{c}\text { Adverse Event Source I } \\
\text { Classification }\end{array}$ & $\begin{array}{l}\text { Subject } \\
\#(\%)\end{array}$ & $\begin{array}{l}\text { Subject } \\
\text { \#(\%) }\end{array}$ & $\begin{array}{l}\text { Subject } \\
\#(\%)\end{array}$ \\
\hline \multicolumn{4}{|l|}{ Self Reported } \\
\hline Oral Irritation & $48(22.6)$ & $51(33.6)$ & $2(3.3)$ \\
\hline Tooth Sensitivity & $91(42.9)$ & $50(32.9)$ & $0(0)$ \\
\hline $\begin{array}{l}\text { Oral Irritation and Tooth } \\
\text { Sensitivity }\end{array}$ & $22(10.4)$ & $20(13.2)$ & $0(0)$ \\
\hline $\begin{array}{l}\text { Oral Irritation or Tooth } \\
\text { Sensitivity }\end{array}$ & $117(55.2)$ & $81(53.3)$ & $2(3.3)$ \\
\hline \multicolumn{4}{|l|}{ Examiner Observed } \\
\hline Oral Irritation & $24(11.3)$ & $34(22.4)$ & $0(0)$ \\
\hline
\end{tabular}

Table 5. Summary of Adverse Events - All Subjects Treated, Nine Clinical Trials.

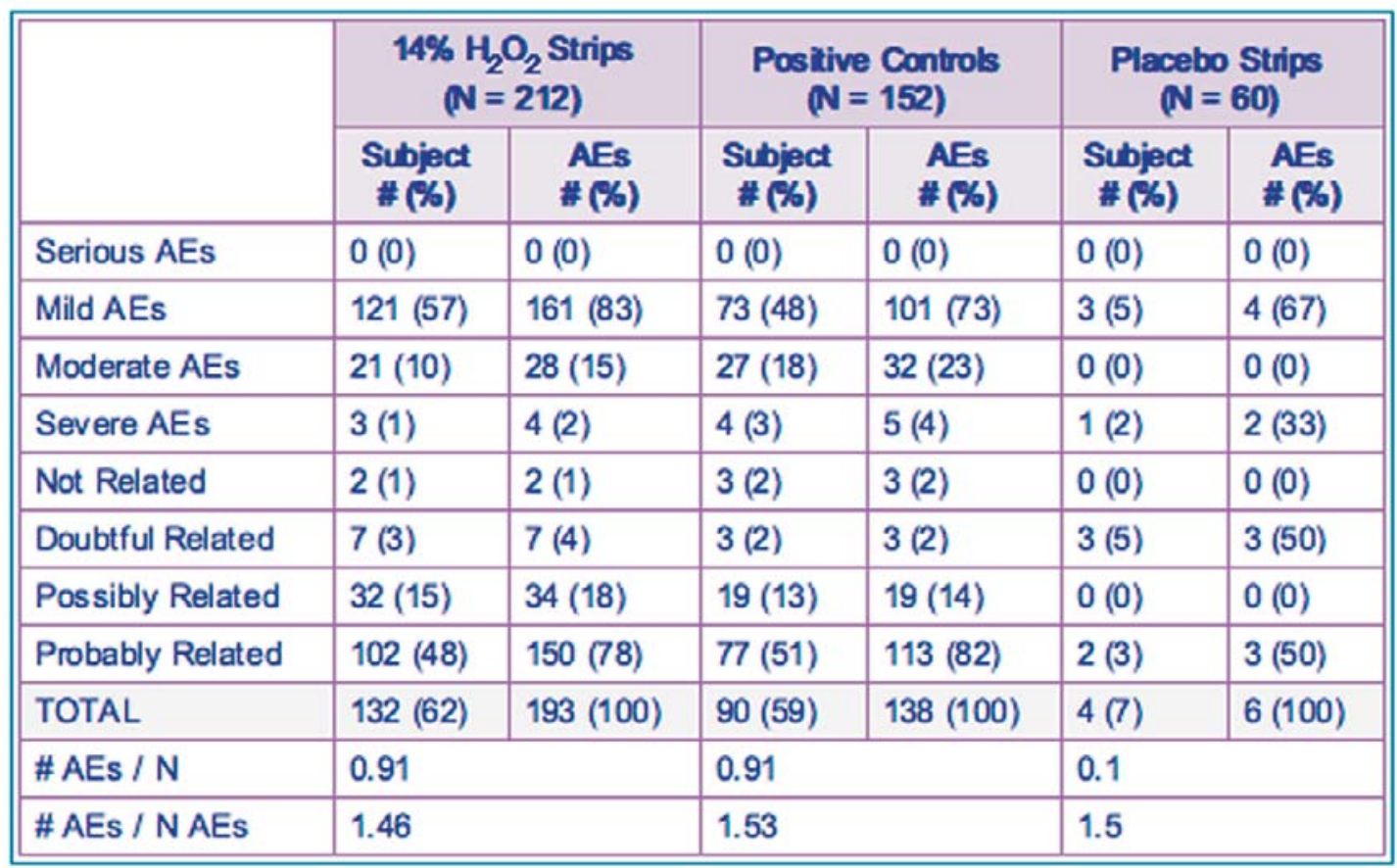


Overall, there were a total of 132 subjects in the pooled $14 \%$ strip group (62\% of the population) with at least one adverse event (related or unrelated to treatment) during the evaluation period (Table 5). The $14 \%$ strip users had on average less than one (0.91) adverse event of any type or causal relationship. Among subjects with adverse events, the total number of reports was limited. The 132 subjects in the $14 \%$ strip group with an adverse event averaged 1.46 adverse events, slightly more than one report per affected subject.

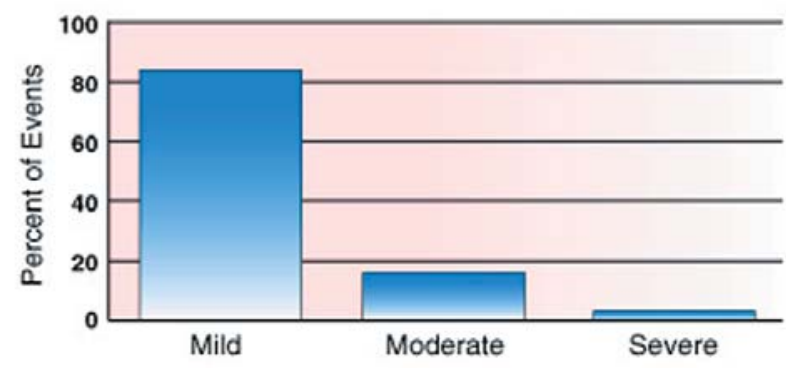

Figure 5. Adverse Event Severity by Causality 14\% hydrogen peroxide strips, All studies

The majority (83\%) of adverse events in the $14 \%$ bleaching strip group were "mild" in severity. Only $2 \%$ of events in the pooled $14 \%$ strip group were classified as "severe," a proportion that was similar to or less than that observed among the positive control or placebo groups (Figure 5). There were no serious adverse events (according to the FDA definition) in any of the trials. Across all studies, only 8 subjects discontinued treatment early because of an adverse event that was possibly or probably related to treatment. By treatment group, the "for cause" drops included 4 subjects (2\% of the group) assigned to $14 \%$ bleaching strips, 3 subjects ( $2 \%$ of the group) assigned to a positive control, and 1 subject ( $2 \%$ of the group) assigned to placebo.

The most common adverse events for $14 \%$ strips were tooth sensitivity and oral irritation. These accounted for $93 \%$ of all adverse events (causal and non-causal) in the pooled $14 \%$ strip group. The most common extraoral adverse event was finger "whitening or tingling" reported for 8 subjects in the $14 \%$ strip group ( $4 \%$ of that population). This mild and transient effect sometimes occurred immediately following strip application. Clinical manifestations were generally mild, and similar to that seen following topical applica- tion of common bottled 3\% hydrogen peroxide. Resolution was within a few minutes to an hour without intervention.

Across all studies, there was only one unusual adverse event - oral leukoplakia seen on examination following use of one of the positive controls - that likely existed pre-treatment. There were no reports of nausea, gastric distress, or other extraoral adverse events in the $14 \%$ hydrogen peroxide strip group except for temporary finger "whitening." Importantly, the research showed no evidence of increased severity with extended use of $14 \%$ strips for up to 6 weeks.

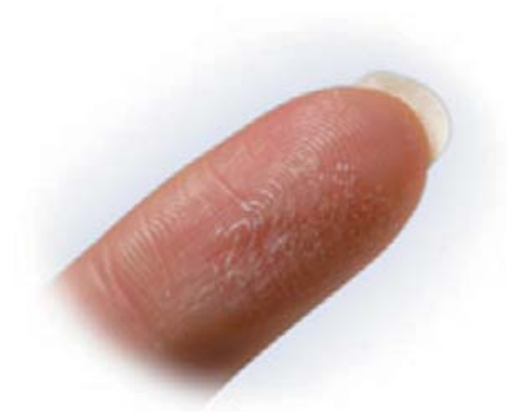

Example of transient finger whitening

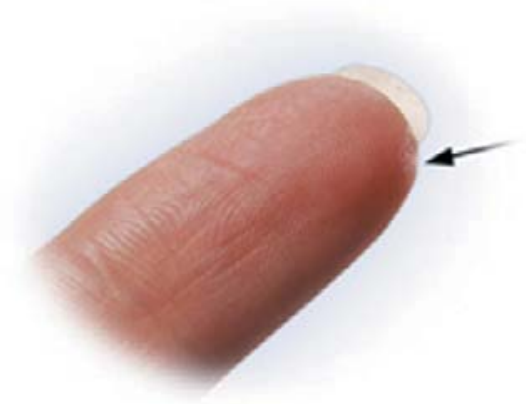

Resolution of whitening

In one comparative study periodontal health was assessed using standard methods for measuring gingivitis (GI) and plaque (PII). Overall, the strip groups had lower mean gingivitis and plaque scores after treatment (Figure 6). Increased plaque and/or gingivitis may provide evidence of oral irritation or other treatment-related adverse events (such as new found tooth sensitivity) that interrupt normal oral hygiene. This research showed no evidence of additional plaque or gingivitis after 3 weeks of treatment with 14\% hydrogen peroxide strips, since periodontal health improved in the absolute. The placebo response 
was generally similar, and there were no significant between-group differences in gingivitis or plaque at any post-baseline time point. As such, the research fails to demonstrate any significant adverse effect of the hydrogen peroxide in higher concentration strips on periodontal health.

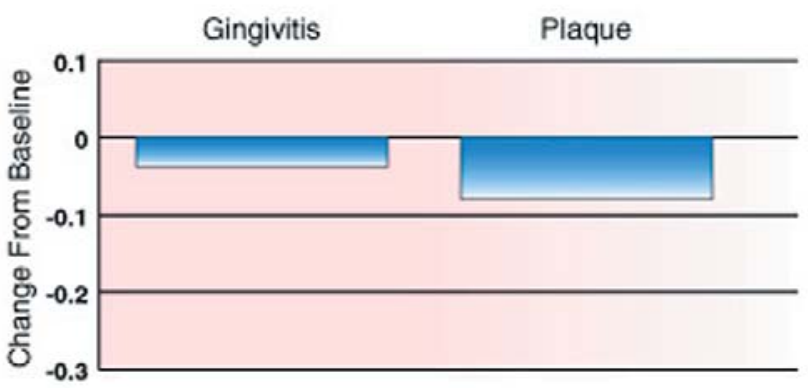

Figure 6. Mean Change in Gingivitis \& Plaque with Treatment $14 \%$ hydrogen peroxide strips

\section{Discussion}

Crest Whitestrips Supreme, a thin 14\% hydrogen peroxide whitening strip, represents a new approach for professional at-home vital bleaching. Characterized as a two-variable change (increased peroxide concentration in the bleaching gel, decreased amount of gel), this 14\% hydrogen peroxide strip carries a relatively similar total amount of peroxide compared to other strip systems. ${ }^{17}$ A total of 9 comparative clinical trials were conducted initially to evaluate clinical response of this novel vital bleaching system.

The integrated results showed Crest Whitestrips Supreme to be both effective (using tooth color or tooth shade as endpoints) and well-tolerated overall. With respect to tooth color, the integrated research demonstrated significant improvements in the individual color parameters $\left(\Delta \mathrm{b}^{*}\right.$ and $\left.\Delta \mathrm{L}^{*}\right)$ as well as composite endpoints $\left(\Delta \mathrm{E}^{\star}\right.$ and $\left.\Delta \mathrm{W}^{*}\right)$ for the $14 \%$ hydrogen peroxide strip. With respect to shade change, twice daily use of the thin concentrated strips resulted in a mean 8-unit shade change after 3 weeks, exceeding pre-established performance criteria in the ADA "Guidelines" for Home-Use Tooth Whitening Products with respect to initial shade improvement. ${ }^{21}$ Results from these studies demonstrate the clinical effectiveness of $14 \%$ hydrogen peroxide bleaching strips is robust and not confined to a single measurement method.
Across all studies, tooth sensitivity and oral irritation represented the most common adverse events with the $14 \%$ hydrogen peroxide strips. Like the preceding research on professional athome vital bleaching with trays or strips, these events were generally mild in severity, and resolved fully during or after treatment. ${ }^{3,14,22,23}$ Also like preceding tray and strip research, there was no evidence of any short-term adverse effects on periodontal health, with gingivitis and plaque scores directionally lower at the end-of-treatment with the $14 \%$ hydrogen peroxide strip..$^{24-26}$ With respect to oral safety and tolerability, the composite research provided no evidence of unexpected or atypical findings for the high concentration whitening strips. Based on this research, use of a low, uniform amount of a higher peroxide concentration gel resulted in a generally similar oral adverse event profile to that seen with other professional at-home vital bleaching systems at lower peroxide concentrations. While extraoral events were infrequent and unremarkable, there was one new finding associated with the higher concentration strip system. Approximately $4 \%$ of subjects in the $14 \%$ hydrogen peroxide group reported some minor and transient post-application finger whitening, proximate to the time of application. The clinical meaningfulness of both the oral and non-oral findings is low given the similar $2 \%$ "for cause" dropout rate in the strip, positive control, and placebo groups.

The integrated research showed generally better efficacy and tolerability for the $14 \%$ hydrogen peroxide strips compared to marketed positive bleaching controls. Individual patient responses varied, as demonstrated in the scatterplot on change in yellowness $\left(\Delta b^{*}\right)$ versus lightness $\left(\Delta L^{*}\right)$. While both the strip and positive control clusters

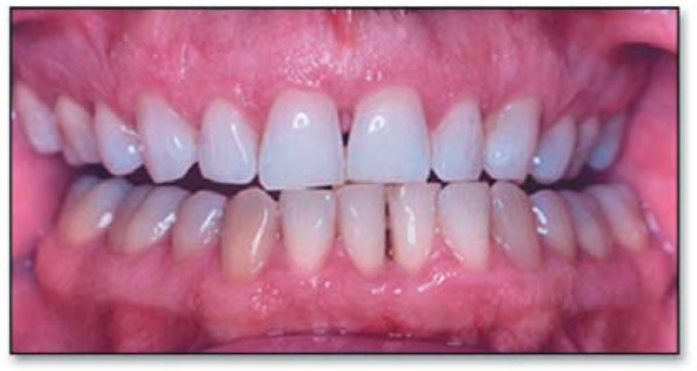

Subject treated with $14 \% \mathrm{H}_{2} \mathrm{O}_{2}$ strips (maxillary arch only) for 3 weeks. Photo courtesy of Dr. Ingvar Magnusson, University of Florida. 
differed from "zero" and placebo (evidence of absolute and relative whitening for these peroxide-containing products), whitening response in the strip group was better overall. The best individual patient responses for $\Delta \mathrm{b}^{*}$ and $\Delta \mathrm{L}^{*}$ were seen among strip users, with these categories differing significantly $(p<0.05)$ with respect to mean color change for $\Delta \mathrm{b}^{*}, \Delta \mathrm{L}^{*}, \Delta \mathrm{E}^{*}$, and $\Delta \mathrm{W}^{*}$. Relative to the other professional whitening systems, the higher concentration strips exhibited similar or better tolerability (tooth sensitivity, oral irritation, examiner-assessed severity, and overall adverse event rates).

What are the advantages of an integrated review? While the randomized clinical trial remains the "gold standard" of research, systematic review and meta-analysis of the outcomes from many trials has long been recognized as providing even a higher level of evidence for use in clinical decision making. ${ }^{27}$ Limitations in this approach, including publication bias, inconsistent reporting, differences in methodologies or populations, and other factors, have been previously described with respect to the dental clinical trials literature..$^{25,28}$ The meta-analysis reported herein, which used original source data from all evaluable subjects in all trials, has fewer limitations. The integrated review, an inclusive assessment of over 200 subjects age 12-70 years, evaluated use of the $14 \%$ hydrogen peroxide strips for periods of up to 6 weeks at 7 different clinical sites. Pooling results from several trials, in addition to increasing sample size, assures greater diversity among the study population and investigators.

The data set was particularly rich in that it includes both placebo and positive controlled studies. The formerdouble-blind placebo trials allowed for the direct assessment of causality, while the latter allowed assessment of relative performance versus products already familiar to many clinicians. ${ }^{29}$ Nonetheless, caution must be taken when interpreting results even from an integrated analysis like this one. Comparative response, especially versus the positive controls, must be an informed one given the dissimilar nature of the various products in that category. For example, professionally-directed, at-home bleaching encompasses a wide range of treatment times (ranging from a few minutes each day to overnight use) and durations (ranging from episodic use over a few days to continuous use over a period of months). ${ }^{30}$ The clinical research summarized herein covered only a portion of these possible combinations, starting first with placebo-control and then moving up through selected higher concentration positive controls. These integrated results substantiate the clinical effectiveness and safety of this novel professional at-home whitening system in the absolute, and relative to contemporary marketed controls.

\section{Conclusions}

- Nine randomized and controlled clinical trials were conducted under the direction of qualified, independent investigators explicitly for the purposes of evaluating Crest Whitestrips Supreme in a diverse population.

- Crest Whitestrips Supreme effectiveness was demonstrated in multiple clinical trials by multiple examiners using different efficacy endpoints (color and shade) both in the absolute and when compared to placebo or the pooled professional at-home bleaching controls.

- Tooth sensitivity and oral irritation, the common adverse events with Crest Whitestrips Supreme use, were generally mild in severity, and resolved during or after treatment.

- Crest Whitestrips Supreme was generally similar to or better than popular, marketed tray-based whitening systems with respect to tolerability (tooth sensitivity, oral irritation, examiner-assessed severity, and overall adverse event rates). 


\section{References}

1. Sagel PA, Odioso LL, McMillan DA, et. al. Vital tooth whitening with a novel hydrogen peroxide strip system: design, kinetics, and clinical response. Compend Contin Educ Dent Suppl. 2000 Jun;(29): S10-5; quiz S42.

2. Gerlach RW. Shifting paradigms in whitening: introduction of a novel system for vital tooth bleaching. Compend Contin Educ Dent Suppl. 2000 Jun;(29):S4-9.

3. Gerlach RW, Zhou X. Vital Bleaching with Whitening Strips: Summary of Clinical Research on Effectiveness and Tolerability. J Contemp Dent Pract 2001 Sep;(2)3: 001-016.

4. Gerlach RW, Gibb RD, Sagel PA. A randomized clinical trial comparing a novel $5.3 \%$ hydrogen peroxide whitening strip to $10 \%, 15 \%$, and $20 \%$ carbamide peroxide tray-based bleaching systems. Compend Contin Educ Dent Suppl. 2000 Jun;(29):S22-8; quiz S42-3.

5. Kugel G, Kastali S. Tooth-whitening efficacy and safety: a randomized and controlled clinical trial. Compend Contin Educ Dent Suppl. 2000 Jun;(29):S16-21; quiz S42.

6. Gerlach RW, Barker ML, Sagel PA. Comparative efficacy and tolerability of two direct-to-consumer tooth whitening systems. Am J Dent. 2001 Oct;14(5):267-72.

7. Donly KJ, Donly AS, Baharloo L, et. al. Tooth whitening in children. Compend Contin Educ Dent. 2002 Jan;23(1A):22-8; quiz 49.

8. Donly KJ, Gerlach RW. Clinical trials on the use of whitening strips in children and adolescents. Gen Dent. 2002 May-Jun;50(3):242-5.

9. Gerlach RW, Barker ML, Sagel PA. Objective and subjective whitening response of two self-directed bleaching systems. Am J Dent. 2002 Sep;15 Spec No:7A-12A.

10. Gerlach RW, Barker ML. Clinical response of three direct-to-consumer whitening products: strips, paint-on gel, and dentifrice. Compend Contin Educ Dent. 2003 Jun;24(6):458, 461-4, 466 passim.

11. Gerlach RW, Gibb RD, Sagel PA. Initial color change and color retention with a hydrogen peroxide bleaching strip. Am J Dent. 2002 Feb;15(1):3-7.

12. Gerlach RW, Sagel PA, Jeffers ME, et. al. Effect of peroxide concentration and brushing on whitening clinical response. Compend Contin Educ Dent. 2002 Jan;23(1A):16-21; quiz 49.

13. Gerlach RW. Zhou X. Comparative clinical efficacy of two professional bleaching systems. Compend Contin Educ Dent. 2002 Jan;23(1A):35-41; quiz 50.

14. Gerlach RW, Zhou X, McClanahan SF. Comparative response of whitening strips to a low peroxide and potassium nitrate bleaching gel. Am J Dent. 2002 Sep;15 Spec No:19A-23A.

15. Karpinia KA, Magnusson I, Sagel PA, et. al. Vital bleaching with two at-home professional systems. Am J Dent. 2002 Sep;15 Spec No:13A-18A.

16. Kugel G, Aboushala A, Zhou X, et. al. Daily use of whitening strips on tetracycline-stained teeth: comparative results after 2 months. Compend Contin Educ Dent. 2002 Jan;23(1A):29-34; quiz 50.

17. Gerlach RW, Sagel PA. Vital bleaching with a thin peroxide gel. The safety and efficacy of a professional-strength hydrogen peroxide whitening strip. J Am Dent Assoc 2004;135;98-100.

18. Weast RC. CRC Handbook of Chemistry and Physics. 64th ed. Boca Raton, FL:CRC Press, Inc;1983:F-79.

19. Gerlach RW, Barker ML, Sagel PA, et. al. In-use comparative kinetics of professional whitening strips: peroxide recovery from strips, teeth, gingiva and saliva. Compend Contin Educ Dent 2004 (In Press).

20. Swift EJ, Miguez PA, Barker ML, Gerlach RW. Three-week clinical trial of a new $14 \%$ hydrogen peroxide strip-based bleaching system. Compend Contin Educ Dent 2004 (In Press).

21. Siew C. ADA guidelines for the acceptance of tooth-whitening products. Compend Contin Educ Dent Suppl. 2000 Jun;(28):S44-7.

22. Haywood VB. History, safety, and effectiveness of current bleaching techniques and applications of the nightguard vital bleaching technique. Quintessence Int. 1992 Jul;23(7):471-88. Review.

23. Li Y. The safety of peroxide-containing at-home tooth whiteners. Compend Contin Educ Dent. 2003 Apr;24(4A):384-9. Review.

24. Kugel G, Kastali S. Tooth-whitening efficacy and safety: a randomized and controlled clinical trial. Compend Contin Educ Dent Suppl. 2000 Jun;(29):S16-21; quiz S42. 
25. Niederman R, Tantraphol MC, Slinin P, et. al. Effectiveness of Dentist-Prescribed, Home-Applied Tooth Whitening. A Meta Analysis. J Contemp Dent Pract 2000;(1)4: 020-036.

26. Almas K, Al-Harbi M. The Effect of a 10\% Carbamide Peroxide Home Bleaching System on the Gingival Health . J Contemp Dent Pract 2003 February;(4)1:032-041.

27. Sackett DL, Rosenberg WM. The need for evidence-based medicine. J R Soc Med. 1995 Nov;88(11): 620-4. Review.

28. Niederman R, Richards D, Matthews D, et. al. International standards for clinical trial conduct and reporting. J Dent Res. 2003 Jun;82(6):415-6. No abstract available.

29. Gerlach RW, Biesbrock AR. Comparative clinical trials and the changing marketplace for oral care: innovation, evidence and implications. Am J Dent. 2002 Sep;15 Spec No:3A-6A.

30. Haywood VB. Frequently asked questions about bleaching. Compend Contin Educ Dent. 2003 Apr;24(4A):324-38.

\section{About the Authors}

\section{Robert W. Gerlach, DDS, MPH}

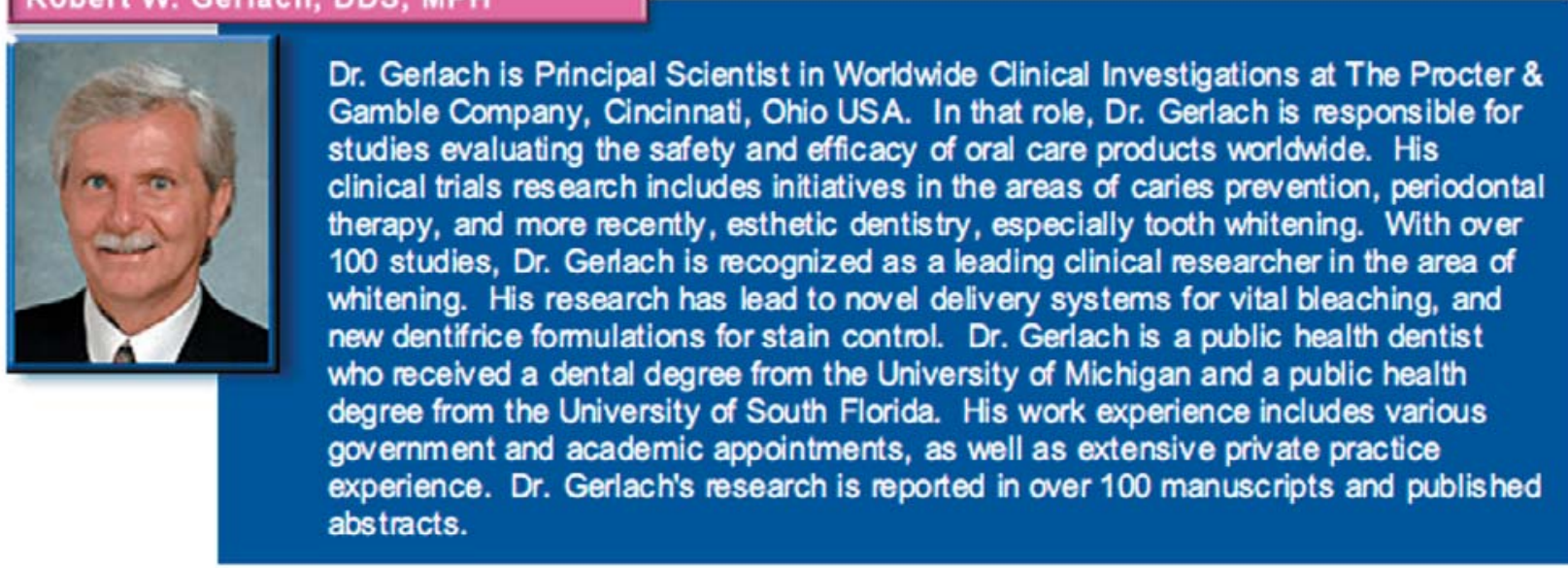

\section{Matthew L. Barker, PhD}

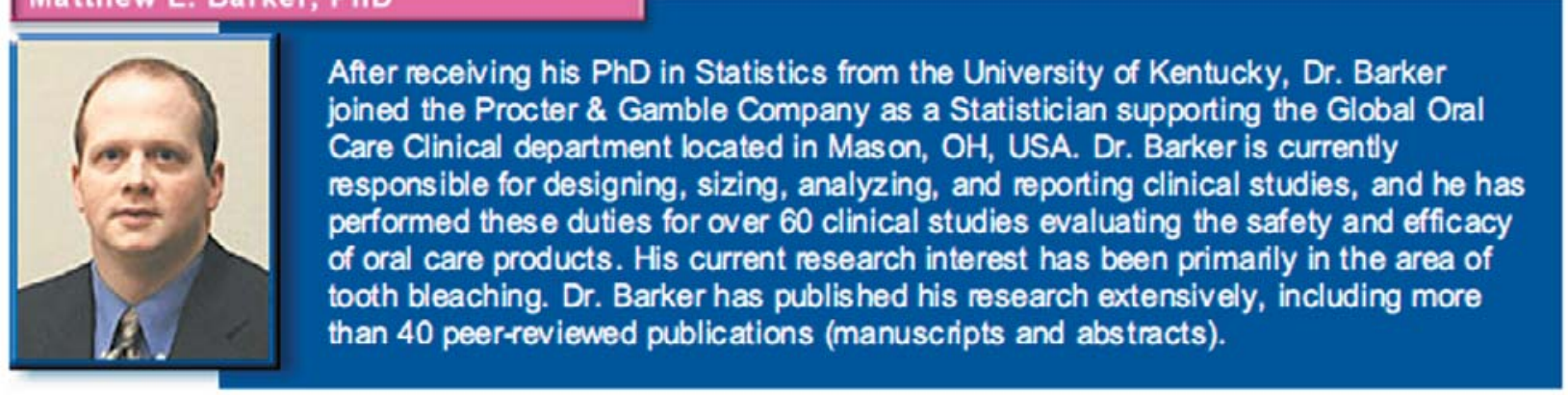

\section{Acknowledgement}

Research of this nature involved contributions by more than 100 individuals at academic institutions and research clinics across North America. In addition to these many researchers, the authors specifically recognize Mary Kay Anastasia, Heidi Tucker, Lisa Prater, Paul Sagel, and Xiaojie Zhou, all of The Procter \& Gamble Company, for their specific contributions on the manuscript. 